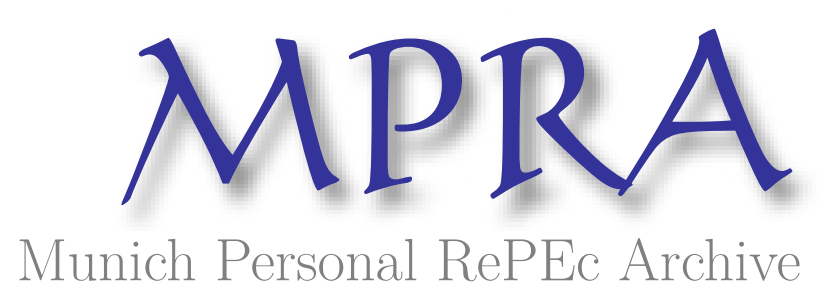

\title{
Drivers Wanted: Motor Voter and the Election of 1996
}

Knack, Stephen

World Bank

1998

Online at https://mpra.ub.uni-muenchen.de/24983/

MPRA Paper No. 24983, posted 14 Sep 2010 16:38 UTC 


\title{
Drivers Wanted: Motor Voter and the Election of 1996
}

\author{
Stephen Knack \\ School of Public Affairs \\ American University \\ 4400 Mass. Ave. NW \\ Washington DC 20016 \\ knack@american.edu
}

Prepared for the 1998 American Political Science Association annual meetings in Boston, MA. 


\section{Introduction}

The cartoon above, printed on the cover of $P S$ in March 1994, has unfortunately proved prophetic. While turnout has steadily declined from its 1960 peak of $63 \%$, the presidential election of 1996 was the first in the lifetime of most Americans in which a minority of the voting-age population voted. ${ }^{`}$ Turnout dropped in every state between `92 and `96.

The $49 \%$ turnout was especially disappointing for advocates of the National Voter Registration Act of 1993 (NVRA), as the most dramatic liberalization of voter registration procedures in American history coincided with not only the lowest level of turnout since 1924, but with the largest single four-year decline since 1920. The theory that registration barriers are the chief cause of the gap between turnout rates of the U.S. and other developed democracies suffered a severe blow: turnout in North Dakota, which doesn't even require voter registration, was a mere $56 \%$ of the voting-age population in 1996.

Moreover, the turnout decline was heavily concentrated among "electorally disadvantaged" groups such as the young, less educated, and residentially mobile (Casper and Bass, 1998). These are the very groups that reform activists expected would be the primary beneficiaries of easier registration.

The NVRA has unquestionably been a spectacular success in adding names to the voter registration rolls (Federal Election Commission, 1997; Human SERVE, 1996). However, the turnout experience of 1996 suggests that very few of these added registrants are bothering to go to the polls.

Before concluding that NVRA has no (or minimal) impact on turnout, however, we must wait until everyone has had the opportunity to register through its new procedures. Most importantly, the key "motor voter" provision requires 3 to 5 years--the typical length of driver's license renewal cycles--for its maximum impact on voting participation to be felt. Analyses of the motor voter programs voluntarily adopted in some states prior to NVRA passage confirms that the effects of motor voter--unlike election-day registration and other reforms--cumulate over several elections (Knack, 1995).

\footnotetext{
${ }^{1}$ Ideally, one would adjust the voting-age population to subtract resident aliens, and convicted felons in states where they are ineligible, and to add eligible citizens living overseas (who count as voters if they vote, but don't enter the voting-age population whether or not they vote). These adjustments would likely produce a small majority of voters among the eligible population.
} 
The view that the NVRA was too new in 1996 to have had any effect on turnout in that election finds some support in data from the November 1996 Current Population Survey (CPS). Based on that survey, the Census Bureau estimated that only $66 \%$ of respondents were registered to vote, the lowest for any presidential election year since 1968 (Casper and Bass, 1998). This estimate is based on self-reports, however, and is likely an underestimate in comparison to earlier years. When registration required more effort and initiative, as in 1968, everyone who registers will remember having done so when queried by Census interviewers. In the 1996 survey, many "motor voter" registrants may not recall having taken those few extra seconds at the motor vehicle or unemployment office to sign the voter registration form. While differences in the way "deadwood" registrants are handled make it impossible to directly compare registration rates in every state across the two elections (Federal Election Commission, 1997; Groarke, 1997), a clear picture emerges from the FEC and Human SERVE reports that nationally the registration rate for 1996 in fact exceeded that of 1992.

Looking at the 1996 election from a national perspective, the tentative conclusion-pending another election or two--is that the NVRA's impact on turnout, and on the participation of underrepresented groups, may be surprisingly small. We can learn more from the 1996 election, however, making use of state-level variation in reform implementation and turnout. While it's true that the entire nation (excepting Vermont) had easy registration in 1996, many states already had easy registration in 1992. If reforms work, we should observe smaller turnout declines in states implementing more extensive reforms between the two elections. Similarly, if reforms disproportionately benefit the young, movers, minorities, and the poor and less educated, the share of all voters that are accounted for by these groups should decline less in reform states than in no-reform states.

The next section presents evidence on NVRA's turnout effects, using state-level data for 1992 and 1996 compiled by Election Data Services, Inc. Section 3 analyzes impacts on the demographic composition of the electorate, using CPS data and exit polling data (from Voter News Services) from the two elections. Also examined are partisan effects, using a party identification item from the exit polls, and official figures on presidential voting by state. Section 4 summarizes.

\section{Turnout in the 1996 Election}

Nationally, the turnout rate for the voting-age population fell by 6.1 percentage points, as shown in the top row of Table 1, using official state voting data compiled by Election Data Services. Dividing states into groups based on their reform experience between the two elections, we discern some indication that registration reform does in fact work. The last eight rows of Table 1 compare the (unweighted) average turnout declines for various state groups.

The first comparison is for five "no-reform" states and the other 46 (including DC). Vermont is the only state that took no measures to come into compliance with NVRA until after the 1996 election. North Dakota has long had no registration requirement, so it was NVRA exempt. Minnesota and Wisconsin had universal election-day registration (EDR) at the polls in 1992 and were also exempted. Maine, usually considered an EDR state, was not exempted because it requires election-day registrants in parts of the state to register at a central location before going to the polls at a separate location to vote. It is classified here as a fifth no-reform state, because the measures it took after 1992 to be NVRA-compliant couldn't possibly have more 
than the most minuscule impact: the vast majority of Maine residents can register at the polls on election day, and Maine has had an effective motor-voter program since before the 1990 election. $^{2}$ The remaining 46 states, which can be thought of as the "experimental" group, all experienced much more substantial reforms than did the 5-state "control" group.

Turnout fell in the 5 non-reform states by an average of 9.6 percentage points, and by only 6.3 points in the 46 reform states. This difference suggests that reforms in fact succeeded, by slowing the turnout decline by 3.3 percentage points on average in the reform states.

\footnotetext{
${ }^{2}$ In recent years, Maine often has been the only state with more registered voters than voting-age residents; obviously some of these were "deadwood" registrants who have moved or died.
} 
Most estimates of the turnout impacts of motor voter and EDR exceed 3.3 points (e.g., Knack, 1995; Rhine, 1995; Fenster, 1994). A possible reason for this relatively low estimate is that not all of the 46 reform states implemented new motor voter or EDR programs. Those with more minor reforms should exhibit a larger turnout decline than those with new motor voter or EDR programs.

Nine (see note to Table 1) of the 46 reform states had effective motor voter programs in place more than six months prior to the 1992 election. ${ }^{3}$ Some of these motor voter programs (e.g., Oregon, DC, Montana, Washington) were not yet "mature" as of November 1992, in the sense of having been in place for a full driver's license cycle. Others among these "old" motor voter states (e.g. Michigan) did not have programs to register applicants for public assistance, or did not have mail-in registration, or purged registrants who didn't vote, until after they began implementing NVRA mandates in 1995 or later. The "no reform" group is thus heterogeneous.

Dividing the reform states into two groups in Table 1, the 9 "old motor voter" states show an average turnout decline of 7.2 percentage points. As expected, turnout fell by somewhat less, 6.0 points, in the 37 states with new motor voter or EDR programs. This decline, coupled with the 9.6-point fall in the 5 no-reform states, suggests that new motor voter or EDR programs have a 3.6-point turnout impact. This estimate still falls a little short of those generated by previous studies. The likely reason is that the key reform in 34 of these 37 states was motor voter, and these programs began only in January 1995 or later, too late for the majority of drivers in most states to have an opportunity, before the 1996 election, to register through driver's license renewal.

One can test this conjecture by dividing these 37 states into two groups: the 34 new motor voter states, and the 3 which opted out of NVRA mandates by instituting EDR between the 1992 and 1996 elections. Unlike motor voter, the full impact of EDR on turnout should be felt immediately, as confirmed by Fenster (1994).

As expected, Table 1 shows that turnout decline in the new EDR states was somewhat more modest (5.3 points) than in the new motor voter states (6.1 points). The new EDR programs appear to have attenuated the turnout decline in Idaho, New Hampshire, and Wyoming by about 4.3 percentage points, comparing their 5.3-point average drop to the 9.6-point drop of the 5 no-reform states. This estimate is close to those generated by other studies such as Fenster (1994).

\footnotetext{
${ }^{3}$ Hawaii (May 1992) and Texas (September 1992) implemented motor voter so soon before the 92 election that they are classified here as "new" rather than "old" motor voter for the ' 96 election. "Passive" motor voter programs that simply made forms available on countertops or upon specific request were ineffective (Knack, 1995) and are not classified here as motor voter programs; see Knack (1995) for more on the distinction between "passive" programs and "active" ones which better approximated the later NVRA mandates. On paper, Ohio, New Jersey and West Virginia were also motor voter states prior to the 1992 election. Because reform advocates at Human SERVE found indications that these programs were administered inconsistently at best, they are not classified as "old" motor voter states here. However, results presented below are not sensitive to how they are classified.
} 
Finally, among the 34 new motor voter states, we would expect to observe larger turnout declines in the states which most strongly resisted and delayed in implementing NVRA mandates. The most obvious way of categorizing such resistance is in terms of legal challenges: 6 of these 34 states challenged NVRA in the courts, generally on constitutionality grounds. ${ }^{4}$

The prediction concerning challengers is the only one not borne out by the data in Table 1 . Turnout decline is actually marginally greater among the 28 non-challengers, on average, than in the 6 challengers.

The before-and-after design of the comparisons in Table 1 minimizes the need for extensive statistical controls that must be included in cross-sectional studies. For example, the above-average levels of income and education characteristic of the 5 no-reform states likely help to explain their above-average turnout levels, but cannot explain their turnout change very easily. To the extent that the U.S. population in all states is aging, and becoming richer, better educated, and less white over time, these changes also will not influence the results.

However, some relevant variables may not change over time equally in all states. Table 2 therefore presents multivariate analyses, to control for spurious factors that conceivably influence turnout. Control variables include changes in per capita income and in the African-American percentage of the population. Both variables have positive but insignificant effects on turnout.

Also added are variables representing changes in the presence of other important contests on a state's ballot. For a state with a Senate race on its ballot in both 1992 and 1996, or in neither year, Senate race is coded 0. For a state with a race in 1992 but not in 1996, the variable is coded -1 ; if it had a race in 1996 but not in 1992, the variable is coded +1 . A gubernatorial variable is coded similarly. The turnout impact of concurrent races proves to be small in Table 9, on the order of 1 percentage point.

Four dummy variables are included to test the impact of registration reform: one each to represent the no reform group, the old motor voter group, the new EDR group, and the challengers. The omitted group is the largest one: the 28 non-challenger new motor voter states.

Equation 1 indicates that turnout fell significantly more--by more than 3 percentage points--in the no reform states than in the 28-state reference group. Turnout fell by nearly a point more in the old motor voter group than in the groups with more extensive reforms, but this difference is not significant.

Equation 2 adds the turnout rate for 1992, to control for any regression-to-the-mean effects. ${ }^{5}$ Results confirm the presence of such an effect: each 6-point increment in 1992 turnout is associated with a (significant) 1-point drop in turnout between 1992 and 1996. The no-reform states had some of the highest turnout rates in 1992, and controlling for this regression-to-the-mean effect reduces the "no reform" coefficient by more than two thirds.

\footnotetext{
${ }^{4}$ Michigan, which invented motor voter and is included among the 9 "old" motor voter states, was nevertheless a seventh challenger, as it sought to prevent having to implement registration of public assistance applicants and other provisions.

${ }^{5}$ If extreme values in any given election tend to represent deviations from the norms for those states, then high (low) levels for 1992 will tend to be associated with declines (increases) between 1992 and 1996.
} 
While none of the four dummies are significant in equation 2, there is still evidence that reform improves turnout. The "new EDR" coefficient more than doubles in equation 2 compared to equation 1. If the new EDR group is made the reference category, one can test whether each of the groups with less extensive reforms exhibit significantly greater rates of turnout decline. The nearly 3-point difference between the new EDR and no reform groups turns out to be significant at the .05 level, while the 2.6-point difference between the new EDR group and the old motor voter group is significant at .10. Multivariate analyses thus confirm that registration reforms associated with NVRA implementation--especially the new EDR programs adopted to avoid NVRA's array of alternative programs--curtailed the great turnout debacle of 1996.

\section{Motor Voter and the Composition of the Electorate}

Turnout decline in 1996 was concentrated in groups that were already underrepresented, particularly the young. Before concluding that NVRA was to blame, or was at a minimum ineffective in equalizing representation, comparisons across groups of states should be conducted, as was done for overall turnout in the previous section. Such comparisons indicated above that registration reform substantially slowed the turnout decline; perhaps they also prevented inequality of representation in the electorate from worsening even more than it did in 1996.

Age

Table 3 reports the turnout rate for respondents in the CPS who are under 30 years of age, as a percentage of the turnout rate for over-30 respondents. This measure of equality of representation would equal $100 \%$ if the turnout rates for the two age categories were the same, and $50 \%$ if the young vote at only half the rate at which older persons do (e.g., a $40 \%$ turnout rate by the young and $80 \%$ by older persons).

In the average state, the young voted at nearly three-quarters of the rate at which over-30 persons voted in 1992. This ratio fell by more than 10 percentage points in 1996 (see top row of Table 3). In the 5 no-reform states, the ratio fell by a stunning 18.6 percentage points. For the 46 reform states, voting rates for the young fell by slightly less than 10 points. The decline in the no-reform group was significantly greater $(\mathrm{p}=.009)$ than in the reform group. The implication is that reform prevented the turnout decline from being even more concentrated among the young than it was.

As expected, equality of representation worsens more in the 9 "old motor voter" states (12.1 points) than in the other 37 reform states ( 9.2 points), although the difference is not statistically significant. Among the 37 states with extensive reforms, the 3 new EDR states actually exhibited a slight increase in equality of representation, in contrast to the 10-point decline in the 34 new motor voter states. This difference $(p=.01)$ is somewhat surprising in light of the fact that the NVRA's key motor voter provision was designed originally to reach young persons (and movers).

Among the 34 new motor voter states, the erosion in equality of representation by age is about equal for the challenger (9.1 points) and non-challenger (10.2 point) groups. The difference between the two declines is not significant.

In addition to CPS data, electorate composition effects can be analyzed using exit polling data from Voter News Serivces (VNS). Since only actual voters are interviewed in exit polls, turnout rates cannot directly be computed from these data. What can be computed is the share of 
the electorate accounted for by a particular group; for example, the percentage of voters in a state who are under 30.

Table 3 shows that the average under-30 share of states' electorates dropped from $19.6 \%$ of voters in 1992 to $16.6 \%$ in 1996 . This 3.3 point drop is matched by similar-sized drops in most groups of states. The prominent exception again is the new EDR states, where the decline in the under-30 share was only 1.6 points. The largest decline, 3.8 points, was in the group of 6 states that refused to implement NVRA until ordered to by the courts. The no-reform states do not stand out in the VNS data as they did in the CPS data for their precipitous drop in equality of representation by age.

The implication from Table 3 is that in the absence of registration reform, representation of the young relative to over-30 voters would have worsened even more than it did. Somewhat surprisingly, EDR appears to have more favorable effects than motor voter for equality of participation for young persons.

\section{Mobility}

Movers and the young are the two groups which Richard Austin, the Michigan Secretary of State in the mid-1970s, was targetting when he designed motor voter. The VNS exit polls did not determine which voters had recently moved, so only CPS data can be employed to examine whether registration reform affected them differently from non-movers. There is little indication in Table 4 that registration reform slowed turnout decline more among movers than among nonmovers. Movers are defined as those living at their current residence for less than one year, while nonmovers have lived at their current address for two years or more.

Equality of representation for movers fell by about 7 percentage points in both the reform and non-reform groups of states. Among the reform states, the decline was slightly smaller in the 37 states with more extensive reforms than in the old motoer voter states, and was slightly smaller in the new EDR states than in the new motor voter states. These differences are not statistically significant, however.

\section{Education}

Exit polls inquired about respondents' education in only 14 states for both 1992 and $1996 .{ }^{6}$ Because educational data are available for so few states from the exit polls, Table 5 relies only on CPS data in examining changes in the equality of representation of Americans without high school diplomas. Table 5 analyzes the turnout rate of CPS respondents without a high school diploma, as a percentage of the turnout rate of high school graduates.

\footnotetext{
${ }^{6}$ Martinez and Hill (forthcoming), who employ a 3-way classification of reform that differs substantially from the state groupings used here, find that the extent of registration reform over the 4-year interim is uncorrelated with changes in the equality of representation by educational category in these 14 states.
} 
Equality of representation by education worsened nationally, as did equality of representation by age and mobility status, although to a lesser degree ( 3.5 percentage points, see top row of Table 5). There is little evidence that registration reform had progressive effects, in the sense of equalizing turnout rates. The representation of the less educated slightly improved in the no reform group ( 0.5 points), while declining by 4 points in the reform group (difference significant at .02). The only good news for reform advocates hoping for enhanced equality of representation is in the 3 new EDR states, which showed a slight improvement ( 0.3 points), compared to a nearly 5-point drop in the 34 new motor voter states, although the difference is insignificant.

\section{Income}

Equality of representation by income did not worsen in 1996, unlike the case for age, education, and mobility. The turnout rate of CPS respondents in households earning under $\$ 15,000$ was about $70 \%$ of the turnout rate for those with higher incomes in 1992, improving to nearly $77 \%$ in 1996 (Table 6, first row). ${ }^{7}$

Exit polling data in Table 6 (first row) appear to contradict this conclusion: the share of under- $\$ 30,000$ earners among voters fell from $40 \%$ to $32 \%$. However, much if not all of this decline is likely attributable to inflation and to economic growth over the four years; even if voting behavior is unchanged, rising incomes will move many voters out of the under- $\$ 30,000$ category.

More extensive reforms are not found to be associated with greater increases in equality of representation by income. The no-reform group, which already had somewhat greater equality, improved slightly more than the reform group. Improvement was somewhat greater in the extensive reform states than in the old motor voter group, consistent with the view that reform improves equality, but the smallest improvement for any group was the one with the most extensive reform: the new EDR states. None of these differences are statistically significant.

The exit polling data in Table 6 likewise show no signs of progressive effects of reform. The low-income share of the electorate fell the most (10.4 points) in the group with the strongest reforms--the new EDR states--and fell the least in the no-reform group (7.4 points) and in the challenger group (6.9 points).

\section{Race}

Because of extremely small CPS sample sizes for minorities in some states (particularly in the new EDR group), turnout rates are not reliable. The exit polling data, while subject to similar problems, at least yield reasonable-looking values, which are presented in Table 7. The share of blacks, and of minorities more generally, in the electorate rose in every group of states, at least in part because population growth over the four-year interval was higher for minorities than for whites.

\footnotetext{
${ }^{7}$ The relative turnout rate of under- $\$ 30,000$ earners to over- $\$ 30,000$ improved by a lesser amount, from $77.7 \%$ to $79.2 \%$
} 
For the 46 reform states and the 34 new motor voter states, increases in the share of blacks and minorities in the electorate are about equal to increases in their shares nationally, suggesting no important equalizing effects. Increases in the groups with the least and most extensive reforms--the 5 no-reform states and the 3 new EDR states--are deceptively small: because of the much smaller base share of minorities in those states, percentage-point increases are bound to be smaller than for other groups of states. For the no-reform states, the roughly $15 \%$ (not percentage point) increase for minorities (from $4.3 \%$ to $5 \%$ ) is about equal to the national average, while the roughly $5 \%$ increase for blacks (from $1.8 \%$ to $1.9 \%$ ) falls slightly short of the national increase for blacks. For the new EDR states, the percentage increases for minorities and blacks respectively are somewhat smaller and somewhat larger than the corresponding increases nationally. On balance, there is little evidence in Table 7 pointing to registration reform as a force for equalizing participation across racial categories.

\section{Partisanship}

The primary advantage of exit polling data over the CPS is that they inquire about partisanship. Table 8 examines changes in the Democratic share of voters who profess loyalty to either major party (independents and others are excluded). The expectation of reform advocates was that new registrants would be disproportionately Democratic. The strongly partisan votes on NVRA in Congress also suggest that Democrats expected to benefit from reform while Republicans feared it.

Table 8 provides absolutely no support for these hopes and fears. Nationally, the Democratic share rose marginally, from 52.8\% to 53.0\%, between 1992 and 1996. Most groups of states also displayed little change in the partisan distribution of voters. Unsurprisingly, deviations from this pattern are observed at the two extremes: the 5 no-reform states and the 3 new EDR states. However, it is the states with the most extensive reforms between 1992 and 1996 that exhibit the largest drop in Democratic loyalties, as the Democratic share declined from 39.8 to $38.1 \%$ in the new EDR group. The states with no reforms, counterintuitively, had the largest increase in the Democratic share, from $50 \%$ to $52.8 \%$.

Presidential voting yields a similar story. The average for Clinton's share of the two-party presidential vote among the states was $52.5 \%$ in 1992 , rising by 1.2 points to $53.7 \%$ in $1996^{8}$ Again, the largest increase (3.6 points) is observed in the 5 states with the least registration reform. By contrast, those with the most extensive reform -- the new EDR states -- had no change in their support for Clinton. The 6 states challenging NVRA in court also bucked the national trend, with a 0.7-point decline in support for Clinton, compared to a 1.9-point rise in the other 28 new motor voter states.

\footnotetext{
${ }^{8}$ Presidential voting data used are the official figures. The exit polling data produce nearly identical values to those reported in Table 8, however, suggesting that the exit polls likely measure other characteristics of the electorate--such as the age distribution--with minimal error.
} 
Because challenging the NVRA does not appear to have impeded its effectiveness in raising turnout, from evidence presented in the previous section, it's doubtful that such challenges could have much influence on the composition of the electorate. However, delayed and half-hearted implementation may have mostly affected programs to register public assistance recipients, rather than registration of licensed drivers. ${ }^{9}$ If so, even small turnout effects could be associated with discernible partisan effects. Knack and White (1998) find that agency registration programs adopted prior to NVRA passage are associated with a significant increase in Democratic registrations.

In that study, Knack and White (1998) examined the relationship between NVRA-type registration programs and the partisan distribution of registrants in the 1976-96 period, in states which register voters by party. They found that the adoption of motor voter programs brought no change in the two-party balance of registrants, but that independent registrations increased substantially. Mail-in registration, also mandated by the NVRA, had no influence on the two-party balance or the proportion of independent registrations. The exit polling data for 1992 and 1996 fail to replicate another finding of Knack and White (1998), that motor voter disproportionately increases independent registrations: the extent of registration reform by states between the last two presidential elections is unrelated to changes in the share of the electorate accounted for by independents. ${ }^{10}$

\section{Multivariate Analyses of Representation}

As argued in section 2 for the case of turnout, the before-and-after research design employed here obviates the need for many control variables that would be important to include in a cross-sectional analysis of the composition of the electorate. For example, the large number of retirees in Arizona and Florida, and the large number of blacks in the South, will affect their shares of under-30 voters and of African-Americans, respectively, in their electorates, but not changes in those shares.

To the extent that changes between 1992 and 1996 in the demographic composition vary across states, these changes could influence the electorate shares estimated from exit polling data. $^{11}$ Although any such changes over a four-year period are likely to be quite small, Table 9 presents regression analyses which control where appropriate for the two demographic variables for which the data are available: per capita income, and percent black. Multivariate analysis also permits controlling for regression-to-the-mean effects.

As mentioned above, the share of the electorate earning less than $\$ 30,000$ falls over time due to inflation and economic growth. Inflation rates are not measured for each state, but we can control for changes in the per capita incomes of states between 1992 and 1996: other things equal, the under- $\$ 30,000$ share should fall more where per capita incomes grew more rapidly.

The dependent variable in equation 1 of Table 9 is the under- $\$ 30,000$ share, from exit

\footnotetext{
${ }^{9}$ Litigation against states for their alleged failure to comply with the NVRA in most cases--including Pennsylvania, one of the 6 challengers--cites programs to register welfare recipients, not licensed drivers.

${ }^{10}$ These results are not shown in tables but are available on request from the author.

${ }^{11}$ Note that such changes will not affect the turnout ratios calculated from CPS data.
} 
polling data. The share is negatively (but not significantly) related to per capita income change, falling by nearly a percentage point for each $\$ 1000$ increase. The 1992 share is also included as an independent variable, to capture regression-to-the-mean effects. As expected, states with initially high shares had significantly greater drops in the share between the two elections.

The extent of registration reform is represented by a set of dummy variables: one for the 5 "no reform" states, one for the 9 "old motor voter" states, one for the 3 "new EDR" states, and one for the 6 "challenger" states. The reference category represents the remaining 28 states, those implementing NVRA reforms without resistance.

If reform has progressive effects, the expectation is that the no reform, old motor voter, and challenger dummies will have negative coefficients in equation 1, while the new EDR coefficient will be positive. Only one of these four predictions is supported in Table 9: challenges are associated with greater declines in the share of low-income earners, but the difference with non-challengers is not significant. The largest difference is between the new EDR states (about 1.7 points below the reference category) and no reform states (1.7 points above). ${ }^{12}$ This 3.4-point difference between those two groups is slightly larger than the corresponding 3-point difference in Table 6 (10.4 vs. 7.4 points). The multivariate analysis thus does not alter our conclusions from Table 6. Differences in income growth across the various groups of states were not hiding any progressive effects of registration reform.

The dependent variable in equation 2 is the African-American share of the electorate. This share increases, as expected, with increases in the percentages of blacks among states' populations between 1992 and 1996, although the increase is not significant. There is no regression-to-the-mean effect, as states with higher African-American shares in 1992 had (slightly and insignificantly) greater increases in the share.

The positive coefficients on the 4 reform dummies in equation 2 indicate that the African-American share of the electorate rose the least in the reference group, the 28 non-challenger new motor voter states. None of the dummies are significant, however, and none are significantly different from each other. The increase in the African-American share of the electorate is uncorrelated with the extent of registration reform.

This conclusion is consistent with those drawn from the comparisons in Table 7. As in the case of underrepresentation of low-income earners in the electorate, conclusions regarding reform and racial representation are unaffected by the inclusion of control variables.

While the Census Bureau and the Survey of Current Business, respectively, annually update their estimates of states' percentages of black residents and of per capita incomes, state-level data on age distribution are provided by the Census Bureau only on a decennial basis. Therefore, Table 9 does not include an equation for under-30 voters. However, the fact that the addition of controls made no difference for income or for race in equations 1 and 2 suggests that the exit poll results presented in Table 3 on voting by the young are likely not driven by differential rates of change in the age distributions of the states.

${ }^{12}$ This difference is not significant at the .05 level (as determined by making one of these groups the reference group, and including a dummy for the 28 non-challenger new motor voter states). 
Equations 3 and 4 address the partisan distribution of the electorate. Because blacks and the poor tend to identify with the Democratic party and vote for its presidential candidates, changes in per capita incomes and in the percentage of black residents perhaps should be controlled for when assessing the impact of registration reform on partisanship. In equations 3 and 4 , each $\$ 1000$ rise in a state's per capita income is associated with a rise of about 1 percentage point in Democratic ID or presidential voting. This result may seem paradoxical: as people become rich, we might expect them to become more Republican. However, a Democrat was in the White House between 1992 and 1996, and we tend to reward or punish incumbents for changes in economic performance occurring during their tenure in office. Therefore, the relative popularity of Democrats could have risen in states with the most rapidly rising incomes, and fallen in states with more stagnant incomes.

Increasing identification with the Democratic party is negatively but insignificantly associated with larger increases in states' percentage of black residents (equation 3). Increases in the Clinton vote are positively and significantly associated with increases in the African-American percentage. No significant regression-to-the-mean effects are observed in equations 3 or 4: changes in Democratic partisanship between 1992 and 1996 are not significantly correlated with their 1992 levels.

Findings from Table 8 on the impact of registration reform on partisanship hold up strongly with the inclusion of these control variables in equations 3 and 4 of Table 9. The Democratic ID share of the electorate significantly fell, by nearly 3 percentage points in the states with the most extensive reform--the new EDR states--relative to the reference group, the 28 non-challenger new motor voter states. The no reform states showed the largest increase, with an edge of more than 2 points over the reference group. Although the "no reform" coefficient does not indicate a significant difference from the reference group, the change in the Democratic ID share for the no reform states is significantly greater than the change in the "old motor voter" and "new EDR" groups (as confirmed by changing which states constitute the reference group). Thus, in all 3 pairwise comparisons of groups in which a significant difference is found, the change in Democratic ID is inversely related to the extent of registration reform.

Evidence on the Clinton vote is more mixed. The Democratic presidential vote share, like its party ID share, increased the most in the no-reform states. It rose significantly more, however, in the non-challenger new motor voter states than in the old motor voter states, as conventional wisdom on the impact of reform would predict. The observed difference between challenger and non-challenger new motor voter states is also consistent with expectations: the Clinton share falls by a significant 2-plus percentage points more in the former group than in the latter group.

While electorate shares calculated from VNS exit polls can be influenced directly by changes in the demographic compositions of states, the same cannot be said for the equality measures constructed from CPS turnout rates (e.g. for movers and nonmovers). Nonetheless, multivariate analyses may be useful in filtering out any regression-to-the-mean effects. For example, perhaps the huge drop in equality of representation by age in the no-reform states shown in Table 2 is related to the very high level of equality in 1992.

In Table 10, the change in the four CPS equality measures are regressed on their initial levels and on the set of reform dummies. Equation 1 shows the results for age. States with higher equality of representation in 1992 have significantly greater declines. Controlling for this regression-to-the-mean effect, the no-reform group does not do as poorly relative to other groups as in Table 3. There is only a 4-point, insignificant difference between the no-reform states and 
the 28-state reference group (the nonchallenger new motor voter states), down from a difference of more than 8 percentage points in Table 3. There is a 10-point difference between the no-reform states and the new EDR states, which is found to be significant at the .05 level when one of these groups is made the reference group. Reform still appears to have progressive effects, although more modest than in the CPS evidence contained in Table 3.

Equation 2 shows that, controlling for a strong regression-to-the-mean effect, that equality between movers and nonmovers worsened the least in the no-reform states and the most in the new EDR states, exactly the opposite of what reform advocates anticipated (although the difference is not significant). In Table 4, the relative turnout of movers actually fell the least in the new EDR states. As shown in Table 4, however, the initial level of equality was very low in the new EDR states, and very high in the no-reform states. Coupled with the very strong regression-to-the-mean effect estimated in equation 2 of Table 10, these initial levels imply that the predicted fall in the no-reform states is very high, while the predicted fall in the new EDR states is very low. Equality in the no-reform states fell by 8 points less than predicted, while falling in the new EDR states by 4 points more than predicted. Because none of the group differences in Table 4 or in equation 2 of Table 10 are significant, one must conclude there is no evidence that reform tended to equalize the large turnout differences between movers and nonmovers.

Table 5 showed that groups of states at either end of the reform spectrum--the no-reform group and the new EDR group--defied the tendency toward declining equality of representation by education. Controlling for initial equality of representation (which is highest in the no-reform group), the edge for the no-reform group over the 28-state reference group increases to a statistically significant 7 percentage points. There is thus little if any evidence from either Table 5 or Table 10 that reform equalized representation by educational category.

Equation 4 also shows strong regression-to-the-mean effects, with states in which equality started off relatively high in 1992 exhibiting larger declines. No significant differences among groups are found, consistent with the results for income categories presented in Table 6. Thus, reform appeared to have no equalizing effects by income class.

Regressions presented in Tables 9 and 10 weight each state equally. Because the CPS and exit polls take much larger samples in some states than in others, some states' estimates are likely to be more accurate than others. Results differ only trivially, however, when states are weighted by the sample size.

\section{Summary}

The first presidential election following NVRA implementation was also the first in the lifetimes of most Americans in which a minority of the voting-age population bothered to vote. While that outcome must be a source of embarrassment to many reform advocates, this study has shown that the turnout decline was in fact substantially slowed by registration reform. Moreover, the full effects of the key "motor voter" innovation have yet to be felt in at least two-thirds of the states, representing more than three quarters of the voting-age population.

Similarly, the disproportionately large turnout decline among the young would have been even more extreme in the absence of reform, based on evidence obtained in this study. Little evidence of other progressive effects--by race, education, income, or mobility status--is found however. 
Finally, although partisan identification and presidential voting moved in the Democrats' direction between 1992 and 1996, registration reform appears to have slightly favored the Republicans. The shift toward Democratic ID and voting was largest in the states with the least reform, while the largest shift away from Democratic ID occurred in the states with the most extensive reform. 


\section{References}

Casper, Lynne and Loretta Bass. 1998. Voting and Registration in the Election of November 1996. Current Population Reports, P20-504. Washington, DC: U.S. Bureau of the Census.

Federal Election Commission. 1997. "The Impact of the National Voter Registration Act of 1993 on the Administration of Federal Elections" (June). Washington, DC: Federal Election Commission.

Fenster, Mark J. 1994. "The Impact of Allowing Day of Registration Voting on Turnout in U.S. Elections from 1960 to 1992." American Politics Quarterly, 22(1): 74-87.

Groarke, Margaret. 1997. “An Early Assessment of the National Voter Registration Act.” Presented at the American Political Science Association annual meetings, August, Washington DC.

Highton, Benjamin and Raymond E. Wolfinger. 1995. Anticipating the Effects of the National Voter Registration Act of 1993.” Presented at the American Political Science Association annual meetings, September, Chicago IL.

Human SERVE. 1996. “The Impact of the National Voter Registration Act, January 1995-June 1996: The First Eighteen Months" (October). New York: Human SERVE.

Knack, Stephen. 1995. “Does Motor Voter Work? Evidence From State Level Data.” Journal of Politics, 57: 796-811.

Knack, Stephen and James White. 1998. "Did States' Motor Voter Programs Help the Democrats?" American Politics Quarterly, 26(3): 344-65.

Martinez, Michael and David Hill (forthcoming). “Did Motor Voter Work?” American Politics Quarterly.

Rhine, Staci L. 1995. "Registration Reform and Turnout Change in the American States." American Politics Quarterly, 23: 409-26.

Voter News Service. 1997. Voter News Service General Election Exit Polls, 1996 [computer file]. ICPSR version. New York, NY: Voter News Service [producer]. Ann Arbor, MI: ICPSR [distributor]. 
Table 1

Turnout Change, 1992-96

\begin{tabular}{|l|c|c|c|}
\hline & $\begin{array}{c}\text { Turnout } \\
1996\end{array}$ & $\begin{array}{c}\text { Turnout } \\
1992\end{array}$ & $\begin{array}{c}\text { Turnout } \\
\text { Change }\end{array}$ \\
\hline All states (weighted by VAP) & 49.0 & 55.1 & -6.1 \\
All states (unweighted) & 51.2 & 57.8 & -6.6 \\
\hline No-reform states (5) & 59.9 & 69.5 & -9.6 \\
Reform states (46) & 50.3 & 56.6 & -6.3 \\
\hline Pre-92 motor voter states (9) & 50.4 & 57.6 & -7.2 \\
Extensive reform states (37) & 50.3 & 56.3 & -6.0 \\
\hline New EDR states (3) & 57.9 & 63.2 & -5.3 \\
New motor voter states (34) & 49.6 & 55.7 & -6.1 \\
\hline Challengers (6) & 47.9 & 53.8 & -5.9 \\
Non-challengers (28) & 50.0 & 56.1 & -6.1 \\
\hline
\end{tabular}

No-reform states are ME, MN, ND, VT, and WI. New EDR states are ID, NH, and WY. Pre-1992 motor voter states are AZ, CO, DC, MI, MT, NC, NV, OR, and WA. Challengers are CA, IL, KS, PA, SC, and VA. 
Table 2

Turnout Change Regressions

\begin{tabular}{|l|c|c|}
\hline & 1 & 2 \\
\hline Intercept & $-6.29 *$ & 3.01 \\
Senate race & 0.70 & $0.86^{*}$ \\
Gubernatorial race & $1.53^{* *}$ & $0.86^{*}$ \\
Change in per capita income & 0.01 & 0.01 \\
Change in \% black & 0.16 & 0.14 \\
No reform & $-3.23^{* *}$ & -0.94 \\
Old motor voter & -0.85 & -0.61 \\
New EDR & 0.81 & 1.99 \\
Challenger & 0.44 & 0.06 \\
Turnout 1992 & & $-0.17 * *$ \\
\hline $\mathrm{R}^{2}$ & 0.27 & 0.42 \\
standard error of estimate & 2.27 & 2.04 \\
\hline
\end{tabular}

A * (**) indicates significant at $.05(.01)$ for 2-tailed test. Sample size is 51. Mean of dependent variable is $-6.63 \%$. 
Table 3

Age and Equality of Representation, 1992-96

\begin{tabular}{|c|c|c|c|c|c|c|}
\hline & \multicolumn{3}{|c|}{$\begin{array}{l}\text { Turnout rate for }<30 \text {, } \\
\text { as } \% \text { of rate for } 30 \text {-and-over (CPS) }\end{array}$} & \multicolumn{3}{|c|}{$<30$ share of electorate $(\mathrm{VNS})$} \\
\hline & $\begin{array}{l}\text { Turnout } \\
\text { ratio } 1996\end{array}$ & $\begin{array}{r}\text { Turnout } \\
\text { ratio } 1992\end{array}$ & $\begin{array}{l}\text { Ratio } \\
\text { change }\end{array}$ & $\begin{array}{l}\text { Share } \\
1996\end{array}$ & $\begin{array}{l}\text { Share } \\
1992\end{array}$ & $\begin{array}{l}\text { Share } \\
\text { change }\end{array}$ \\
\hline 51-state unweighted mean & 63.2 & 73.8 & -10.6 & 16.6 & 19.6 & -3.3 \\
\hline No-reform states (5) & 66.3 & 84.9 & -18.6 & 17.0 & 20.5 & -3.5 \\
\hline Reform states (46) & 62.9 & 72.6 & -9.7 & 16.2 & 19.6 & -3.4 \\
\hline Pre-92 motor voter states (9) & 61.8 & 73.9 & -12.1 & 17.2 & 20.4 & -3.2 \\
\hline Extensive reform states (37) & 63.1 & 72.3 & -9.2 & 19.3 & 16.0 & -3.3 \\
\hline New EDR states (3) & 61.4 & 60.9 & +0.5 & 17.3 & 18.9 & -1.6 \\
\hline New motor voter states (34) & 63.3 & 73.3 & -10.0 & 15.9 & 19.4 & -3.5 \\
\hline Challengers (6) & 63.9 & 73.0 & -9.1 & 14.9 & 18.7 & -3.8 \\
\hline Non-challengers (28) & 63.1 & 73.3 & -10.2 & 16.1 & 19.5 & -3.4 \\
\hline
\end{tabular}


Table 4

Mobility and Equality of Representation (CPS), 1992-96

Turnout rate for mobile as $\%$ of rate for nonmobile

\begin{tabular}{|c|c|c|c|}
\hline & $\begin{array}{r}\text { Turnout } \\
\text { ratio 1996 }\end{array}$ & $\begin{array}{r}\text { Turnout } \\
\text { ratio 1992 }\end{array}$ & $\begin{array}{r}\text { Ratio } \\
\text { change }\end{array}$ \\
\hline 51-state unweighted mean & 63.1 & 70.2 & -7.1 \\
\hline No-reform states (5) & 70.3 & 77.3 & -7.0 \\
Reform states (46) & 62.4 & 69.5 & -7.1 \\
\hline Pre-92 motor voter states (9) & 64.5 & 72.9 & -8.4 \\
Extensive reform states (37) & 61.8 & 68.6 & -6.8 \\
\hline New EDR states (3) & 57.6 & 61.3 & -3.7 \\
New motor voter states (34) & 62.2 & 69.3 & -7.1 \\
\hline Challengers (6) & 62.5 & 69.5 & -7.0 \\
Non-challengers (28) & 62.1 & 69.2 & -7.1 \\
\hline
\end{tabular}


Table 5

Education and Equality of Representation, 1992-96 (CPS)

Turnout rate for non-high school graduates as $\%$ of rate for high school graduates

\begin{tabular}{|c|c|c|c|}
\hline & $\begin{array}{c}\text { Turnout } \\
\text { ratio 1996 }\end{array}$ & $\begin{array}{c}\text { Turnout } \\
\text { ratio 1992 }\end{array}$ & $\begin{array}{c}\text { Turnout } \\
\text { change }\end{array}$ \\
\hline 51-state unweighted mean & 64.1 & 67.6 & -3.5 \\
\hline No-reform states (5) & 71.6 & 71.1 & +0.5 \\
Reform states (46) & 63.2 & 67.2 & -4.0 \\
\hline Pre-92 motor voter states (9) & 60.0 & 62.5 & -2.5 \\
Extensive reform states (37) & 64.0 & 68.3 & -4.3 \\
\hline New EDR states (3) & 65.0 & 64.7 & +0.3 \\
New motor voter states (34) & 63.9 & 68.7 & -4.8 \\
\hline Challengers (6) & 64.9 & 68.5 & -3.6 \\
Non-challengers (28) & 63.7 & 68.7 & -5.0 \\
\hline
\end{tabular}


Table 6

Turnout Change: Income $<\$ 30,000,1992-96$

\begin{tabular}{|c|c|c|c|c|c|c|}
\hline & \multicolumn{2}{|c|}{ CPS } & \multicolumn{3}{l|}{ Exit Polls } \\
& $\begin{array}{c}\text { Turnout } \\
\text { ratio 1996 }\end{array}$ & $\begin{array}{c}\text { Turnout } \\
\text { ratio 1992 }\end{array}$ & $\begin{array}{c}\text { Turnout } \\
\text { change }\end{array}$ & $\begin{array}{c}\text { Share } \\
1996\end{array}$ & $\begin{array}{c}\text { Share } \\
1992\end{array}$ & $\begin{array}{c}\text { Share } \\
\text { change }\end{array}$ \\
\hline 51-state unweighted mean & 76.7 & 70.3 & +6.4 & 32.1 & 40.1 & -8.0 \\
\hline No-reform states (5) & 80.6 & 73.6 & +7.0 & 36.0 & 43.4 & -7.4 \\
Reform states (46) & 76.3 & 69.9 & +6.3 & 31.7 & 39.8 & -8.1 \\
\hline Pre-92 motor voter states (9) & 74.9 & 70.3 & +4.6 & 32.9 & 41.6 & -8.7 \\
Extensive reform states (37) & 76.6 & 69.8 & +6.8 & 39.3 & 31.3 & -8.0 \\
\hline New EDR states (3) & 77.5 & 73.5 & +4.0 & 32.9 & 43.3 & -10.4 \\
New motor voter states (34) & 76.5 & 69.5 & +7.0 & 31.2 & 39.0 & -7.8 \\
\hline Challengers (6) & 78.3 & 68.1 & +10.2 & 27.2 & 34.1 & -6.9 \\
Non-challengers (28) & 76.1 & 69.8 & +6.3 & 32.0 & 40.0 & -8.0 \\
\hline
\end{tabular}


Table 7

Turnout Change: Minorities, 1992-96 (Exit Polls)

\begin{tabular}{|c|c|c|c|c|c|c|}
\hline & \multicolumn{2}{|l|}{ Non-Whites } & \multicolumn{2}{l|}{ Blacks } \\
\hline & $\begin{array}{c}\text { Share } \\
1996\end{array}$ & $\begin{array}{c}\text { Share } \\
1992\end{array}$ & $\begin{array}{c}\text { Share } \\
\text { change }\end{array}$ & $\begin{array}{c}\text { Share } \\
1996\end{array}$ & $\begin{array}{c}\text { Share } \\
1992\end{array}$ & $\begin{array}{c}\text { Share } \\
\text { change }\end{array}$ \\
\hline 51-state unweighted mean & 16.6 & 14.3 & +2.3 & 8.9 & 8.3 & +0.6 \\
\hline No-reform states (5) & 5.0 & 4.3 & +0.7 & 1.9 & 1.8 & +0.1 \\
Reform states (46) & 17.9 & 15.4 & +2.5 & 9.6 & 9.0 & +0.6 \\
\hline Pre-92 motor voter states (9) & 20.2 & 17.2 & +3.0 & 12.5 & 10.8 & +1.7 \\
Extensive reform states (37) & 17.3 & 14.9 & +2.4 & 8.9 & 8.5 & +0.4 \\
\hline New EDR states (3) & 4.7 & 4.4 & +0.3 & 0.9 & 0.6 & +0.3 \\
New motor voter states (34) & 18.4 & 15.9 & +2.5 & 9.6 & 9.2 & +0.4 \\
\hline Challengers (6) & 16.1 & 18.2 & +2.1 & 12.0 & 10.9 & +1.1 \\
Non-challengers (28) & 18.5 & 15.8 & +2.7 & 9.2 & 8.9 & +0.3 \\
\hline
\end{tabular}


Table 8

Turnout Change: Partisanship, 1992-96

\begin{tabular}{|c|c|c|c|c|c|c|}
\hline & \multicolumn{3}{|c|}{ Democratic ID (exit polls) } & \multicolumn{3}{c|}{ Democratic presidential vote } \\
\hline & $\begin{array}{c}\text { Share } \\
1996\end{array}$ & $\begin{array}{c}\text { Share } \\
1992\end{array}$ & $\begin{array}{c}\text { Share } \\
\text { change }\end{array}$ & $\begin{array}{c}\text { Share } \\
1996\end{array}$ & $\begin{array}{c}\text { Share } \\
1992\end{array}$ & $\begin{array}{c}\text { Share } \\
\text { change }\end{array}$ \\
\hline 51-state unweighted mean & 53.0 & 52.8 & +0.2 & 53.7 & 52.5 & +1.2 \\
\hline No-reform states (5) & 52.8 & 50.0 & +2.8 & 57.4 & 53.8 & +3.6 \\
Reform states (46) & 53.0 & 53.1 & -0.1 & 53.3 & 52.4 & +0.9 \\
\hline Pre-92 motor voter states (9) & 54.1 & 55.2 & -1.1 & 56.3 & 57.1 & -0.8 \\
Extensive reform states (37) & 52.8 & 52.6 & +0.2 & 52.6 & 51.2 & +1.4 \\
\hline New EDR states (3) & 38.1 & 39.8 & -1.7 & 45.8 & 45.8 & +0.0 \\
New motor voter states (34) & 54.1 & 53.7 & +0.4 & 53.2 & 51.7 & +1.5 \\
\hline Challengers (6) & 49.1 & 48.8 & +0.3 & 51.3 & 52.0 & -0.7 \\
Non-challengers (28) & 55.2 & 54.8 & +0.4 & 53.5 & 51.6 & +1.9 \\
\hline
\end{tabular}


Table 9

Electorate Composition Regressions (VNS)

\begin{tabular}{|l|c|c|c|c|}
\hline & \multicolumn{3}{|c|}{ Dep. variable: pct. point change in electorate share } \\
\hline & $\begin{array}{c}\text { Under } \\
\$ 30000\end{array}$ & Black & $\begin{array}{c}\text { Democrat } \\
\text { ID }\end{array}$ & $\begin{array}{c}\text { Democratic } \\
\text { Pres. Vote }\end{array}$ \\
\hline Intercept & $9.90^{*}$ & -0.39 & 1.07 & $-5.42^{*}$ \\
Change in per capita income & -0.87 & & $0.85^{*}$ & 1.02 \\
Change in \% black & $-0.38^{* *}$ & & -0.78 & $1.36^{*}$ \\
$<\$ 30,000$ share, 1992 & & 0.06 & & \\
Black share, 1992 & & & -0.05 & \\
Democratic ID share, 1992 & 1.70 & 0.32 & 2.08 & 2.05 \\
Dem. pres. vote share, 1992 & 0.10 & 1.49 & -2.06 & $-2.62^{*}$ \\
No reform & -1.68 & 0.63 & $-2.69 *$ & -0.37 \\
Old motor voter & -1.10 & 0.75 & -0.62 & $-2.36^{*}$ \\
New EDR & 0.38 & 0.10 & 0.17 & 0.36 \\
Challenger & -8.05 & 0.63 & 0.24 & 1.18 \\
\hline $\mathrm{R}^{2}$ & & & & \\
mean, dependent variable & & & & \\
\hline
\end{tabular}

A * (**) indicates significant at $.05(.01)$ for 2-tailed test. Sample size is 51. 
Table 10

Turnout Ratio Regressions (CPS)

\begin{tabular}{|l|c|c|c|c|}
\hline & \multicolumn{4}{|c|}{ Dependent variable: change in turnout ratio } \\
\hline & $\begin{array}{c}\text { Age } \\
\text { ratio }\end{array}$ & $\begin{array}{c}\text { Mobility } \\
\text { ratio }\end{array}$ & $\begin{array}{c}\text { Education } \\
\text { ratio }\end{array}$ & $\begin{array}{c}\text { Income } \\
\text { ratio }\end{array}$ \\
\hline Intercept & 17.02 & $61.21^{* *}$ & 38.68 & $60.52^{* *}$ \\
1992 ratio & $-0.37^{*}$ & $-0.98^{* *}$ & $0.85^{* *}$ & $-0.78^{* *}$ \\
No reform & -4.12 & 8.05 & $7.00^{* *}$ & 3.66 \\
Old motor voter & -1.67 & 2.32 & -1.43 & -1.30 \\
New EDR & 6.07 & -4.45 & 2.76 & 0.55 \\
Challenger & 0.96 & 0.33 & 1.26 & 2.54 \\
\hline $\mathrm{R}^{2}$ & 0.37 & 0.56 & 0.29 & 0.51 \\
mean, dependent variable & -10.06 & -7.08 & -3.52 & 6.40 \\
\hline
\end{tabular}

$\mathrm{A} *(* *)$ indicates significant at $.05(.01)$ for 2-tailed test. Sample size is 51 . 